Article

\title{
Impacts of the Qinghai-Tibet Railway on Accessibility and Economic Linkage of the Third Pole
}

\author{
Shicheng $\mathrm{Li}^{1,2}{ }^{\mathbb{D}}$, Jian Gong ${ }^{1, *}$, Qinghai Deng ${ }^{3}$ and Tianyu Zhou ${ }^{4}$ \\ 1 Department of Land Resource Management, School of Public Administration, \\ China University of Geosciences, Wuhan 430074,China; lisc@cug.edu.cn \\ 2 Key Laboratory of Land Surface Pattern and Simulation, Institute of Geographic Sciences and Natural \\ Resources Research, Chinese Academy of Sciences, Beijing 100101, China \\ 3 Shandong Provincial Key Laboratory of Depositional Mineralization and Sedimentary Mineral, \\ College of Earth Science and Engineering, Shandong University of Science and Technology, \\ Qingdao 266590, China; dqh2004@163.com \\ 4 School of Earth Sciences, China University of Geosciences, Wuhan 430074, China; tianyuzhou1119@126.com \\ * Correspondence: gongjian@cug.edu.cn; Tel.: +86-027-67883223
}

Received: 19 September 2018; Accepted: 30 October 2018; Published: 31 October 2018

check for updates

\begin{abstract}
Constructing the Qinghai-Tibet Railway (QTR) was a landmark project and was beneficial to the sustainable development of the Third Pole. To understand the sustainable development of remote regions by the provision of railway, we studied the QTR's impact on accessibilities and economic linkages for four cities in the Third Pole, Xining, Golmud, Nagqu, and Lhasa, and between these four cities and 29 capital cities in mid-eastern China. First, employing average shortest travel time (ASTT) and weighted average travel time (WATT) as indicators, we calculated the railway-based accessibilities for June 2006 and January 2013. Then, using a gravity model, railway-based economic linkages were determined. The results demonstrate that: (i) ASTT for Xining-Golmud decreased by $4.14 \mathrm{~h}$ from June 2006 to January 2013. Both ASTT and WATT indicated that the accessibilities of the four cities and between these four cities and 29 capital cities in mid-eastern China improved significantly, and the spatial disparity in accessibility for the four cities decreased, which increased the balance and sustainability of the transportation system; (ii) the average contribution rate of the QTR to improving economic linkages for six routes among the four cities was $25.29 \%$, with the Xining-Nagqu and Nagqu-Lhasa linkages improving most significantly; (iii) the QTR strengthened economic linkages between the four cities and mid-eastern cities. Because of the QTR, the economic linkages between the four cities and 29 capital cities increased $27.58 \%$ on average. The spatial disparity in interurban economic linkages also decreased. Transporting products from Tibet should be promoted to strengthen the sustainability of economic growth.
\end{abstract}

Keywords: Qinghai-Tibet Railway; accessibility; economic linkage; highland city; gravity model; spatial disparity; Tibetan Plateau

\section{Introduction}

The Tibetan Plateau is known as the Asian Highlands and Third Pole of the world [1,2]. The main body of the Tibetan Plateau lies in western China. Compared with mid-eastern China, the Tibetan Plateau has a harsh natural environment, sparse population, and lagging economic level. Specifically, the population of Qinghai Province and the Tibet Autonomous Region (hereafter shortened to Tibet) only accounted for $0.63-0.67 \%$ of China's population from 2006 to 2016 [3-5]. Furthermore, the gross domestic product (GDP) for the two provinces only accounted for $0.42-0.50 \%$ of China's national GDP for 2006-2016 [3-5]. The number of cities on the Tibetan Plateau is also very 
small compared with the mid-eastern regions, and the GDP and population of Lhasa and Xining rank low compared with other capital cities in China.

The railway network density in western China is also far lower than that in mid-eastern China [6]. Tibet was the last province in China to accommodate trains, due to its high altitude and complex terrain. In August 2006, with the opening of the Golmud-Lhasa section of the Qinghai-Tibet Railway (QTR), trains were introduced to Tibet. By the end of 2015, the railway network density for Qinghai and Tibet reached $14.7 \mathrm{~km} / 10^{4} \mathrm{~km}^{2}$, while the corresponding value for China was $125 \mathrm{~km} / 10^{4} \mathrm{~km}^{2}$ [7], indicating the railway transportation conditions on the Tibetan Plateau remained low and unsustainable in the long run [8].

The QTR is a milestone project $[9,10]$, and the Xining-Golmud section of the QTR has been open to traffic for nearly 35 years, with the whole line open to traffic for more than 10 years. The understanding on how the QTR affects the accessibility and interurban economic linkages in the Third Pole should be addressed. In this study, we focus on how introducing transport infrastructure to remote areas improves the accessibility and promotes the economy of remote cities. Constructing the QTR was achieved with sustainable development as a top project priority, making it a green railway [11,12]. Therefore, this study also analyzes how green and sustainable railways promote local economic development and comes up with some suggestions about sustainable transportation development of the Third Pole. The most valuable contribution of this paper to the existing literature is the calculation of contribution rate of the QTR to the growth of economic linkages in the Third Pole. In practice, our results can provide guidance for sustainable transportation and urban planning in the Third Pole and western China.

The structure of this study is as follows. First, the literature concerning railway-based accessibility, socioeconomic development, and the effects of the QTR on socioeconomic development is reviewed. Then more information about the QTR is provided in order to facilitate understanding of the QTR and Third Pole. Subsequently, the materials and methods are introduced in detail and are followed by a results section. The last two sections of this paper are discussion and recommendations, and conclusions.

\section{Literature Review}

The linkages between transport infrastructure investment and accessibility change or economic performance have various characteristics [13-17]. As one of the main modes of transportation, railways influence regional sustainable development by reducing transportation costs [18-20], improving accessibility and economic linkages [20-24], and increasing competitiveness and sustainability of a system [19,23]. In addition, the short- and long-term impacts of railroads on urban growth are different [25]. It is also show that the economic effects of railway show great variability as economic effects are conditional upon a set of other factors, including city size, industry structures, and distance from the urban core [26]. In addition, the structuring effect of the train network on cities demographics is discussed and a case study in French for 1860-1910 is available [27].

For China, due to the development of inter-city railways in the Greater Pearl River Delta of China starting in 1990 and construction of the Bohai Strait Cross-Sea Channel, accessibility improved and total economic linkages were strengthened $[16,28]$. Railway network expansion in China has significantly improved economic development and influenced the formation of urban systems [6,15]. Specifically, the positive effect of rail network density on regional economic growth is found to be significant in the east and north of China and the positive effect of accessibility change is found to be more significant in the Middle Reaches of Yangtze River [29]. Interestingly, one recent study also found that railway infrastructure falls short of other physical capital in promoting aggregate output in China [30]. Additionally, China's high-speed rail facilitate market integration, mitigate the cost of megacity growth, and improve the sustainability of development [19,22]. In addition, the accessibility benefit of high-speed rail is not distributed evenly. Second-tier cities with relatively large population bases benefit more from high-speed rail in attracting investment compared with small cities and mega 
cities [31]. Most above-mentioned studies have focused on railway concentrated areas, with little research on development in remote regions where transportation conditions are lagging [6,31,32], including the Tibetan Plateau [32] and Central Asia [33].

As the first railway introduced to the Third Pole, the QTR has received considerable attention, with most research on the associated ecological and environmental issues [34-38], while accessibility and socioeconomic-related studies are rare. Only several initial qualitative studies on this theme can be found, which do not fully reflect the socioeconomic influences of the QTR. For example, suggestions concerning QTR construction and sustainable socioeconomic development of Tibet were provided to local governments by members of the Chinese Academy of Science based on expert knowledge [39]. The QTR connects Lhasa with other major cities via the extensive railway network of China, thereby facilitating the economic and social development in Tibet [40]. By comparing socioeconomic factors between surrounding and non-surrounding areas of the QTR before and after its construction, $\mathrm{Li}$ et al. [32] found that an integrated and sustainable transport system will form with the construction of the QTR, and the GDP of surrounding areas of the QTR had a greater growth rate than non-surrounding areas. However, the population was not aggregated into the surrounding areas, which is not sustainable in the long run. Employing a difference-in-difference method, Wang et al. [41] found that the GDP of the surrounding regions of the QTR increased by more than $20 \%$ after the completion of the railway, mainly through manufacturing changes. Li et al. [18] concluded that the QTR increased the GDP of Tibet by $8 \%$ for 2006-2013 using a grey forecasting model GM $(1,1)$, which is a model for predicting systems with uncertainties. The miraculous development of the tourism industry had prominent effects on economic development and urbanization in Lhasa (Tibet) after 2006 due to the running of the QTR [42]. It can be concluded that the cited studies related to the impacts of railway network on accessibility or economic performance focused solely on national level or the mid-eastern regions of China, and the QTR was not included [6,17,43], or the economic effects were not fully addressed. However, assessing the QTR's socioeconomic influences is beneficial to sustainable transport and urban planning in the Third Pole, because it was the first railway constructed in the Third Pole $[7,39,40]$.

In this study, the impacts of the QTR on accessibilities and economic linkages of cities in the Third Pole were determined. We calculated the railway-based accessibility and its change from June 2006 to January 2013 employing average shortest travel time (ASTT) and weighted average travel times (WATT) as indicators. Subsequently, using a gravity model, the ASTT-based interurban economic linkages and changes were estimated for four cities in the Third Pole, Xining, Golmud, Nagqu, and Lhasa, and the contribution rate of the QTR to the increases of economic linkage was determined. The results are discussed further and suggestions for sustainable growth of economic linkages are given.

\section{The Qinghai-Tibet Railway}

Prior to 1955, freight could only be transported into Tibet by camel, and from 1955, highways were available. Railway construction began in 1978 [11]. The construction of the QTR was part of the China Western Development strategy, an attempt to develop western regions of China that were much less developed than eastern China. As the world's highest-elevation railway, with a total length of $1956 \mathrm{~km}$, the QTR has been considered a landmark green project $[9,10]$. The length of railway with an elevation higher than $4000 \mathrm{~m}$ is $960 \mathrm{~km}$, and about $550 \mathrm{~km}$ of track is laid on permafrost. The line includes the Tanggula Pass, which, at $5072 \mathrm{~m}$ above sea level, is the world's highest point on a railway line. The railway crosses the source regions of the Yangtze, Yellow, Yarlung Zangbo, Nu-Salween, and Lancang-Mekong Rivers (Figure 1).

The QTR connects Xining, the capital city of Qinghai Province, to Lhasa, the capital city of Tibet. The first section of the QTR, which was opened to traffic in 1984, began at Xining and ended at Golmud, with a length of $814 \mathrm{~km}$ (hereafter shortened to XG; Figure 1). The second section of the QTR, which was inaugurated and opened to regular trial service in July 2006, begins at Golmud and 
ends at Lhasa, with a length of $1142 \mathrm{~km}$ (hereafter shortened to GL; Figure 1). Five trains arrive at and depart from the Lhasa Railway Station each day [40]. The XG section is double track and the GL section is single track. Electric locomotives are used for the $X G$ section, but diesel-powered locomotives are still used for the GL section, which limits increases in transport capacity. The QTR is the only railway linking the Tibetan Plateau to mid-eastern China. The opening to traffic of the QTR effectively relieved the pressure of highway transportation. Railway freight kilometers were higher than highway freight kilometers in 1990-2013 [32], significantly reducing transport pollution and improving the sustainability of transportation system and economic development in the Third Pole. In addition, the QTR has been termed a green railway and is carefully managed to ensure sustainability on the Tibetan Plateau [11,12].

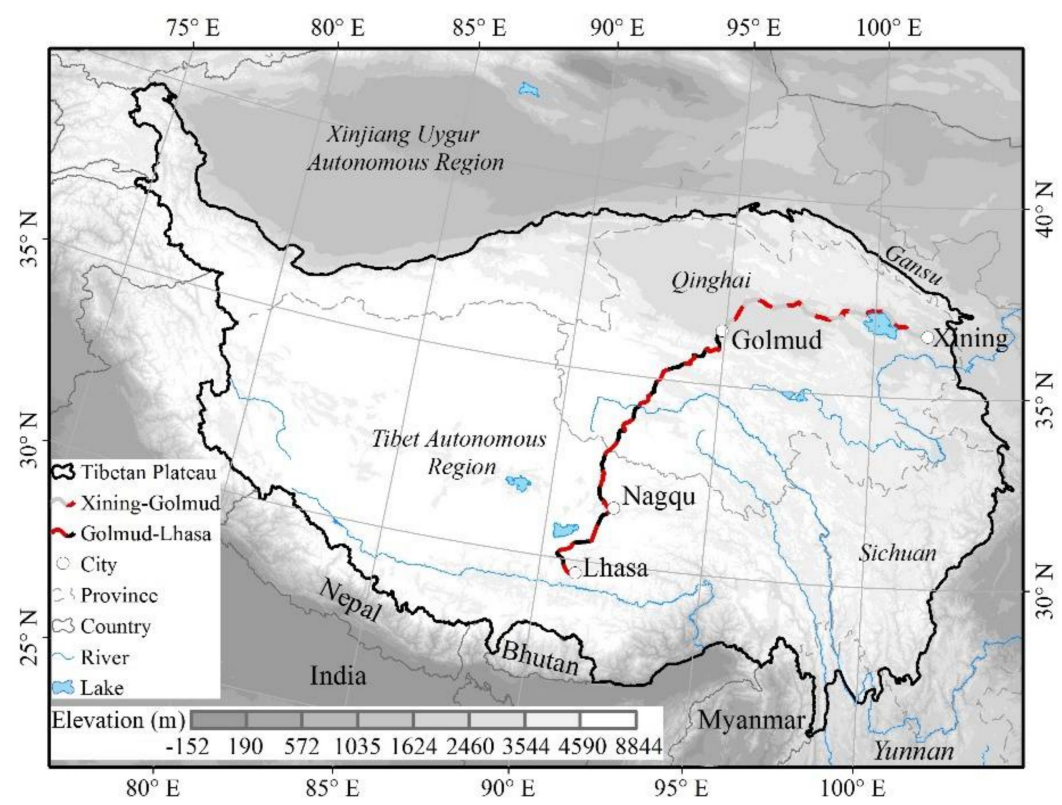

Figure 1. Location map of the Qinghai-Tibet Railway and the four highland cities in the Third Pole.

\section{Materials and Methods}

\subsection{Analysis of Railway-Based Accessibility}

The construction and opening of railway traffic naturally change accessibility [20]. First, we analyzed railway-based accessibility, its changes in the four highland cities within the Third Pole and between the Third Pole and 29 capital cities in mid-eastern regions of China due to the QTR. A wide variety of indicators are used to measure accessibility [44,45]. For example, Curtis et al. [46] conducted a comprehensive review of different accessibility definitions and measures, including spatial separation, contour, gravity, competition, time-space, utility, and network measures. Both ASTT and WATT are frequently used accessibility indicators [20]. Specifically, ASTT is the basic unit to measure accessibility from the perspective of travel cost. Compared with ASTT, WATT considers both the travel cost and attractiveness (e.g., population, employment, and gross domestic product) of a city, as different cities have different attractiveness to passengers [20]. Two basic accessibility indicators, ASTT and WATT, were selected in this study. WATT is as follows [20]:

$$
\mathrm{WATT}_{i}=\sum_{j=1}^{n}\left(A S T T_{i j} \times M_{j}\right) / \sum_{j=1}^{n} M_{j}
$$

where $W_{A T T}$ is weighted average travel times of city $i$, with lower values indicating greater accessibility. $A S T T_{i j}$ is average shortest travel time between cities $i$ and $j ; n$ is the total number of destinations from city $i ; M_{j}$ is the mass of the destination city $j$, indicating the attractiveness and radiation capacity of the 
city to its surrounding areas $[20,21]$. In previous studies, only population or gross domestic product (GDP) has been used as an indicator of city mass. In this study, $M_{j}$ is calculated using the geometric mean of population and GDP $[21,28,47]$, which involves a more comprehensive consideration of economic and social information for a given city. The equation is as follows:

$$
M_{j}=\sqrt{P_{j} \times G_{j}}
$$

where $P_{j}$ is the population of city $j$ and $G_{j}$ is GDP of city $j$. Population denotes the number of people the city served, and GDP denotes economy size of the city.

The QTR passes through four representative highland cities, Xining, Golmud, Nagqu and Lhasa, which were selected based on city size and data availability to calculate their railway-based accessibilities for June 2006 and January 2013. Xining and Lhasa are the capital cities of Qinghai Province and Tibet, respectively. Golmud is the second-largest city in Qinghai Province, and Nagqu is the second-largest city in Tibet that the QTR passes through. In addition, their railway-based accessibilities to 25 provincial capitals and four municipalities (hereafter, 29 capital cities) were calculated. The 29 capital cities are Beijing, Shanghai, Tianjin, Chongqing, Harbin, Changchun, Shenyang, Hohhot, Shijiazhuang, Urumqi, Lanzhou, Xi'an, Yinchuan, Zhengzhou, Jinan, Taiyuan, Hefei, Wuhan, Changsha, Nanjing, Chengdu, Guiyang, Kunming, Nanning, Hangzhou, Nanchang, Guangzhou, Fuzhou, and Haikou (Figure 2).

\subsection{Analysis of Economic Linkages}

Improving accessibility strengthens interurban economic linkages $[13,15,23,24]$. These economic linkages can reflect the capacity of an economic center to influence its surrounding areas and the surrounding areas to influence their economic center [24,28]. Therefore, after analyzing accessibility and its change due to the opening to traffic of the QTR, we analyzed ASTT-based interurban economic linkages and their variations.

Economic linkage indicates the intensity of economic spatial interaction. Economic spatial interaction refers to the exchange of materials, energy, people, funds and information among cities in order to maintain the normal production and life [24]. Due to the distance-decayed law of the economic spatial interaction, the gravity model has been widely used in economics, including regional economics, economic geography, and international trade to calculate the intensity of economic spatial interaction [47-50]. In addition, in economic geography, the gravity model is also called the economic linkage intensity model [24]. The gravity model, described as Equation (3), is used in this study to calculate the ASTT-based economic linkages between the four cities within the Third Pole and the four cities to the 29 capital cities in China for June 2006 and January 2013. Equation (4) is used to calculate the total economic linkage for city $i$.

$$
\begin{gathered}
E L_{i j}=\left(M_{i} \times M_{j}\right) / A S T T_{i j}^{2} \\
E L_{i}=\sum_{j=1}^{n} E L_{i j}
\end{gathered}
$$

where $E L_{i j}$ is the railway-based economic linkage between cities $i$ and $j$. Economic linkage units are 100 million Yuan 10 thousand person $/ h^{2} . E L_{i}$ is the total railway-based economic linkage for city $i$, reflecting the intensity of economic linkage of city $i$ with other cities. The $A S T T_{i j}$ is the railway-based average shortest travel time between cities $i$ and $j$.

In Equation (3), the railway-based economic linkage between cities $i$ and $j$ increase as long as the population and GDP increase, even if the ASTT remains unchanged. To determine the percentage of increase of railway-based economic linkage due to the improvement in accessibility by the QTR, Equation (5) was employed.

$$
R_{Q T R}=\frac{E L_{Q T R}-E L_{t 1}}{E L_{t 2}-E L_{t 1}} \times 100 \%
$$


where $R_{Q T R}$ is the percentage of increase in economic linkage because of the improvement in railway-based accessibility. $E L_{t 1}$ and $E L_{t 2}$ are interurban economic linkages for $t_{1}$ and $t_{2}$, respectively, and $E L_{t 1}-E L_{t 2}$ is the improvement in total economic linkage for period $t_{1}-t_{2}$, including the total impacts of increases in GDP and population and improved accessibility due to the QTR. EL QTR is the economic linkage calculated using population and GDP for $t_{1}$ and ASTT for $t_{2}$, and $E L_{Q T R}-E L_{t 2}$ is the economic linkage improvement for period $t_{1}-t_{2}$ due only to the QTR, excluding the impacts of increases in GDP and population.

\subsection{Data Sources}

The ASTTs for June 2006 and January 2013 were obtained from the official timetable of China's Ministry of Railway (http://www.jpskb.com/). The shortest travel times were chosen from all direct railway services between two cities. For links with no direct railway service, a transfer station was selected based on the shortest distance between two cities. When travel times upstream and downstream were different because of different railway scheduling, the average of the two travel times was calculated as the final ASTT.

Population and GDP data for Xining, Golmud, Nagqu, and Lhasa for 2006 and 2013 were obtained from statistical yearbooks for Qinghai and Tibet [51-54]. Population and GDP data for the 29 capital cities were obtained from China City Statistical Yearbooks [55,56].

\section{Results}

\subsection{Accessibilities among the Four Cities within the Third Pole}

In June 2006, the ASTT between Xining and Golmud was $13.08 \mathrm{~h}$ and routes to Nagqu or Lhasa were inaccessible by railway (Table 1). In January 2013, the ASTT between Xining and Golmud was $8.94 \mathrm{~h}$, a $4.14 \mathrm{~h}$ decrease from June 2006 to January 2013, or 31.65\%. Shortening the travel time improved the accessibility between the four cities within the Third Pole. The ASTTs for Xining-Nagqu, Xining-Lhasa, Golmud-Nagqu, Golmud-Lhasa, and Nagqu-Lhasa are provided in Table 1.

Table 1. Average shortest travel time (ASTT) between the four cities within the Third Pole for June 2006 and January 2013.

\begin{tabular}{ccccc}
\hline \multirow{2}{*}{ Routes } & \multicolumn{2}{c}{ ASTT (h) } & \multicolumn{2}{c}{ ASTT Decrease } \\
\cline { 2 - 5 } & June 2006 & January 2013 & Absolute & $\%$ \\
\hline Xining-Golmud & 13.08 & 8.94 & 4.14 & 31.65 \\
Xining-Nagqu & inaccessible & 18.73 & - & - \\
Xining-Lhasa & inaccessible & 22.83 & - & - \\
Golmud-Nagqu & inaccessible & 9.22 & - & - \\
Golmud-Lhasa & inaccessible & 13.43 & - & - \\
Nagqu-Lhasa & inaccessible & 3.53 & - & - \\
\hline
\end{tabular}

In June 2006, the WATTs for Xining, Golmud, Nagqu, and Lhasa were unmeasurable because the GL section of the QTR had not yet opened to traffic. In January 2013, the WATTs for Xining, Golmud, Nagqu, and Lhasa were 18.42 h, 9.92 h, 14.57 h, and 19.71 h, respectively. The accessibility for Golmud was best, followed by Nagqu.

\subsection{Accessibilities of the Four Cities within the Third Pole to the 29 Capital Cities in Mid-Eastern China}

The shortest travel times between the four cities within the Third Pole and the 29 capital cities for June 2006 and January 2013 are illustrated in Figure 2. In June 2006, the shortest travel times between Xining and the 29 capital cities were lower than these for Golmud, indicating that the railway-based accessibility of Xining was better than Golmud at that time. The shortest travel time between Xining and its surrounding cities, including Lanzhou, $\mathrm{Xi}^{\prime}$ an, Yinchuan, and Zhengzhou, was lower, and the 
shortest travel time between Xining and cities located in southern China, including Nanning, Haikou, Hangzhou, Fuzhou, and Guangzhou, was higher. A similar spatial disparity was also found for Golmud (Figure 2a).

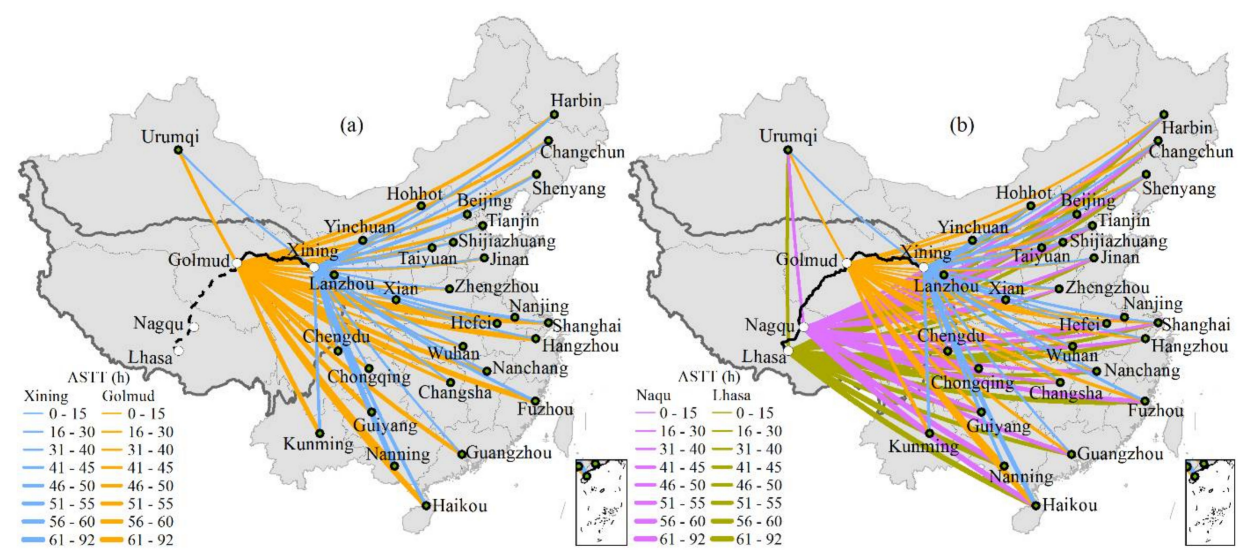

Figure 2. Shortest travel times between the four cities within the Third Pole and the 29 capital cities in mid-eastern China: (a) June 2006 and (b) January 2013.

Nagqu and Lhasa gained access by railway to the 29 capital cities in January 2013. The shortest travel time for Xining remained the lowest, indicating that the railway-based accessibility for Xining was best in the four cities, followed by Golmud, Nagqu, and Lhasa. The shortest travel time between the four cities and 29 capital cities in January 2013 shared similar spatial disparity with those in June 2006 (Figure 2b).

From June 2006 to January 2013, the ASTTs for Xining and Golmud to the 29 capital cities decreased by $16.78 \%$ and $21.60 \%$, respectively (Table 2 ), indicating that the QTR improved the accessibility for Golmud more significantly. Of the 29 cities, 18 had their shortest travel time with Xining reduced by more than $5 \mathrm{~h}$ and there are also 18 cities in 29 whose shortest travel time with Golmud reduced by more than $10 \mathrm{~h}$. Particularly, the shortest travel times for Xining-Nanning, Xining-Harbin, Golmud-Hangzhou, Golmud-Haikou, Golmud-Nanning, and Golmud-Nanchang decreased by $17.70 \mathrm{~h}, 10.32 \mathrm{~h}, 28.97 \mathrm{~h}, 26.41 \mathrm{~h}, 21.52 \mathrm{~h}$, and $21.25 \mathrm{~h}$, respectively. In addition, inequalities in accessibility of the four cities to the 29 capital cities decreased. Specifically, the ASTT ratio between Xining and Golmud decreased from 1.55 in June 2006 to 1.36 in January 2013, which increased the sustainability of the transportation system on the Third Pole.

Table 2. Average shortest travel time (ASTT) between the four cities within the Third Pole and the 29 capital cities in mid-eastern China for June 2006 and January 2013.

\begin{tabular}{ccccc}
\hline \multirow{2}{*}{ Cities } & \multicolumn{2}{c}{ ASTT (h) } & \multicolumn{2}{c}{ ASTT Decrease } \\
\cline { 2 - 5 } & June 2006 & January 2013 & Absolute & \% \\
\hline Xining & 30.25 & 25.17 & 5.07 & 16.78 \\
Golmud & 46.84 & 34.22 & 12.62 & 21.60 \\
Nagqu & inaccessible & 44.20 & - & - \\
Lhasa & inaccessible & 48.13 & - & - \\
\hline
\end{tabular}

Considering the city weights, WATTs for the four cities to the 29 capital cities were calculated (Table 3) and the results were similar to the ASTT results. In June 2006, WATT values for Xining and Golmud to the 29 capital cities were $30.65 \mathrm{~h}$ and $46.33 \mathrm{~h}$, respectively. The corresponding value for January 2013 decreased by about 20.36\% and 27.50\%, respectively, compared with those for June 2006 (Table 3). The WATT ratio between Xining and Golmud decreased from 1.51 to 1.38, also indicating the inequalities in accessibility for the four cities to the 29 capital cities decreased and a balanced and sustainable transportation system on the Third Pole was coming. 
Table 3. Weighted average travel time (WATT) between the four cities within the Third Pole and the 29 capital cities in mid-eastern China for June 2006 and January 2013.

\begin{tabular}{ccccc}
\hline \multirow{2}{*}{ Cities } & \multicolumn{2}{c}{ WATT (h) } & \multicolumn{2}{c}{ WATT Decrease } \\
\cline { 2 - 5 } & June 2006 & January 2013 & Absolute & \% \\
\hline Xining & 30.65 & 24.41 & 6.24 & 20.36 \\
Golmud & 46.33 & 33.59 & 12.74 & 27.50 \\
Nagqu & inaccessible & 43.81 & - & - \\
Lhasa & inaccessible & 47.50 & - & - \\
\hline
\end{tabular}

\subsection{Economic Linkages among the Four Cities within the Third Pole}

In June 2006, the economic linkage between Xining and Golmud was 39.24 (Table 4). Because Nagqu and Lhasa were inaccessible by railway, their railway-based economic linkage was 0. In January 2013, the economic linkage between Xining and Golmud improved to 360.59, an increase of 321.35, with 44.75 being due to the improvement in railway-based accessibility, accounting for $13.93 \%$.

The economic linkages for Xining-Nagqu, Xining-Lhasa, Golmud-Nagqu, Golmud-Lhasa, and Nagqu-Lhasa increased by $75.75,114.96,45.98,48.86$, and 652.12 , respectively, with $22.51-31.53 \%$ being due to the opening of traffic of the QTR (Table 4). The QTR contributed most to improving economic linkages for Xining-Nagqu and Nagqu-Lhasa. In addition, the QTR improved economic linkages for the six city pairs by an average of $25.29 \%$.

Table 4. Railway-based economic linkages among the four cities within the Third Pole for June 2006 ( $E L_{t 1}$ ) and January $2013\left(E L_{t 2}\right)$, and the contribution rate of the Qinghai-Tibet Railway $\left(R_{Q T R}\right)$. Economic linkage units are 100 million Yuan 10 thousand person $/ \mathrm{h}^{2}$.

\begin{tabular}{lcccc}
\hline \multicolumn{1}{c}{ Routes } & $\boldsymbol{E} \boldsymbol{L}_{\boldsymbol{t 1}}$ & $\boldsymbol{E} \boldsymbol{L}_{\mathbf{Q T R}}$ & $\boldsymbol{E} \boldsymbol{L}_{\boldsymbol{t} \mathbf{2}}$ & $\boldsymbol{R}_{\mathbf{Q T R}} \mathbf{( \% )}$ \\
\hline Xining-Golmud & 39.24 & 83.99 & 360.59 & 13.93 \\
Xining-Nagqu & 0 & 23.88 & 75.75 & 31.53 \\
Xining-Lhasa & 0 & 30.08 & 114.96 & 26.16 \\
Golmud-Nagqu & 0 & 12.47 & 45.98 & 27.12 \\
Golmud-Lhasa & 0 & 11.00 & 48.86 & 22.51 \\
Nagqu-Lhasa & 0 & 198.70 & 652.12 & 30.47 \\
\hline
\end{tabular}

$E L_{Q T R}$ : economic linkage only considering the improvement of railway-based accessibility, which was calculated using population and GDP for 2006 and average shortest travel time for 2013.

From June 2006 to January 2013, the total economic linkages for the four cities within the Third Pole increased significantly (Table 5). The total economic linkages improved $19.28-30.37 \%$ due to the opening of traffic the QTR, with particularly significant improvements in Nagqu and Lhasa, indicating that the GL section of the QTR has promoted the economic growth of cities in Tibet. The average contribution rate of the QTR to the improving economic linkages within the four cities was $23.86 \%$. In addition, it can also be seen that the inequality in railway-based total economic linkages decreased for the study period.

Table 5. Railway-based total economic linkages for the four cities within the Third Pole for June $2006\left(E L_{t 1}\right)$ and January $2013\left(E L_{t 2}\right)$, and the contribution rate of the Qinghai-Tibet Railway $\left(R_{Q T R}\right)$. Economic linkage units are in 100 million Yuan 10 thousand person $/ \mathrm{h}^{2}$.

\begin{tabular}{lcccc}
\hline Cities & $\boldsymbol{E} \boldsymbol{L}_{\boldsymbol{t} \mathbf{1}}$ & $\boldsymbol{E} \boldsymbol{L}_{\mathbf{Q T R}}$ & $\boldsymbol{E \boldsymbol { L } _ { \boldsymbol { t } \mathbf { 2 } }}$ & $\boldsymbol{R}_{\boldsymbol{Q T R}} \mathbf{( \% )}$ \\
\hline Xining & 39.24 & 98.71 & 551.30 & 19.28 \\
Golmud & 39.24 & 68.22 & 455.43 & 16.39 \\
Nagqu & 0 & 235.05 & 773.85 & 30.37 \\
Lhasa & 0 & 239.78 & 815.94 & 29.39 \\
\hline
\end{tabular}




\subsection{Economic Linkages of the Four Cities in the Third Pole to the 29 Capital Cities in Mid-Eastern China}

The railway-based economic linkages of the four cities within the Third Pole to the 29 capital cities are shown in Figure 3. As shown, Xining had better economic linkages with the 29 capital cities than Golmud for 2006 (Figure 3a). Using GDP and population for 2006 and ASTT for 2013, we calculated the economic linkages only considering improvement in railway-based accessibility (Figure 3b). The economic linkages of the four cities to the 29 capital cities for 2013 are illustrated in Figure 3c.

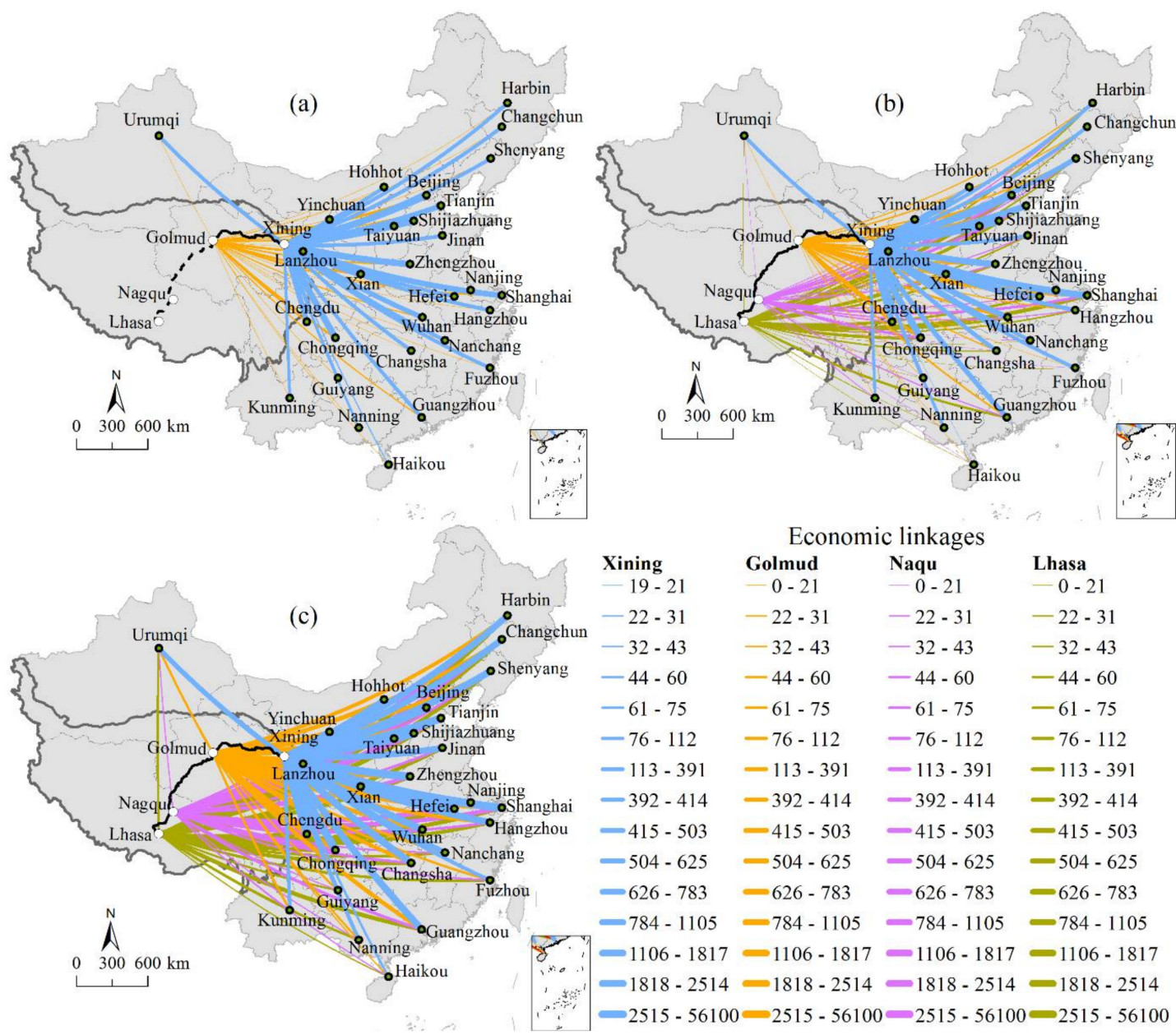

Figure 3. Railway-based economic linkages of the four cities within the Third Pole to the 29 capital cities: (a) for June 2006; (b) only considering the improvement in railway-based accessibility from June 2006 to January 2013; and (c) for January 2013.

Figure $3 b, c$ both show that Xining had the best economic linkages to the 29 capital cities, Golmud and Lhasa had close economic linkage to the 29 capital cities, and Nagqu had the smallest. In addition, Figure $3 \mathrm{a}-\mathrm{c}$ indicates clear and similar spatial inequality in economic linkages between the four cities and the 29 capital cities. Economically, the four cities were linked tightly with large cities, e.g., Beijing, Shanghai, and Tianjin, and closer-proximity cities, e.g., Chongqing, Lanzhou, and Xi'an, and linkages were poor with cities in southern China, including Guiyang, Kunming, Nanjing, Nanchang, Fuzhou, and Haikou.

Railway-based economic linkages between the Third Pole and the 29 capital cities significantly improved from June 2006 to January 2013 (Figure 4). Xining showed the largest improvement in railway-based economic linkages, followed by Lhasa, Nagqu, and Golmud (Figure 4a). Spatial disparities in improvements in railway-based economic linkages are also observed. For all four cities, improvements in economic linkages to big cities, including Beijing, Shanghai, and Tianjin, and close-proximity or 
transportation-hub cities, including Chongqing, Chengdu, Lanzhou, Xi'an, Shijiazhuang, Zhengzhou, and Wuhan, were significant while those to southern cities were not.

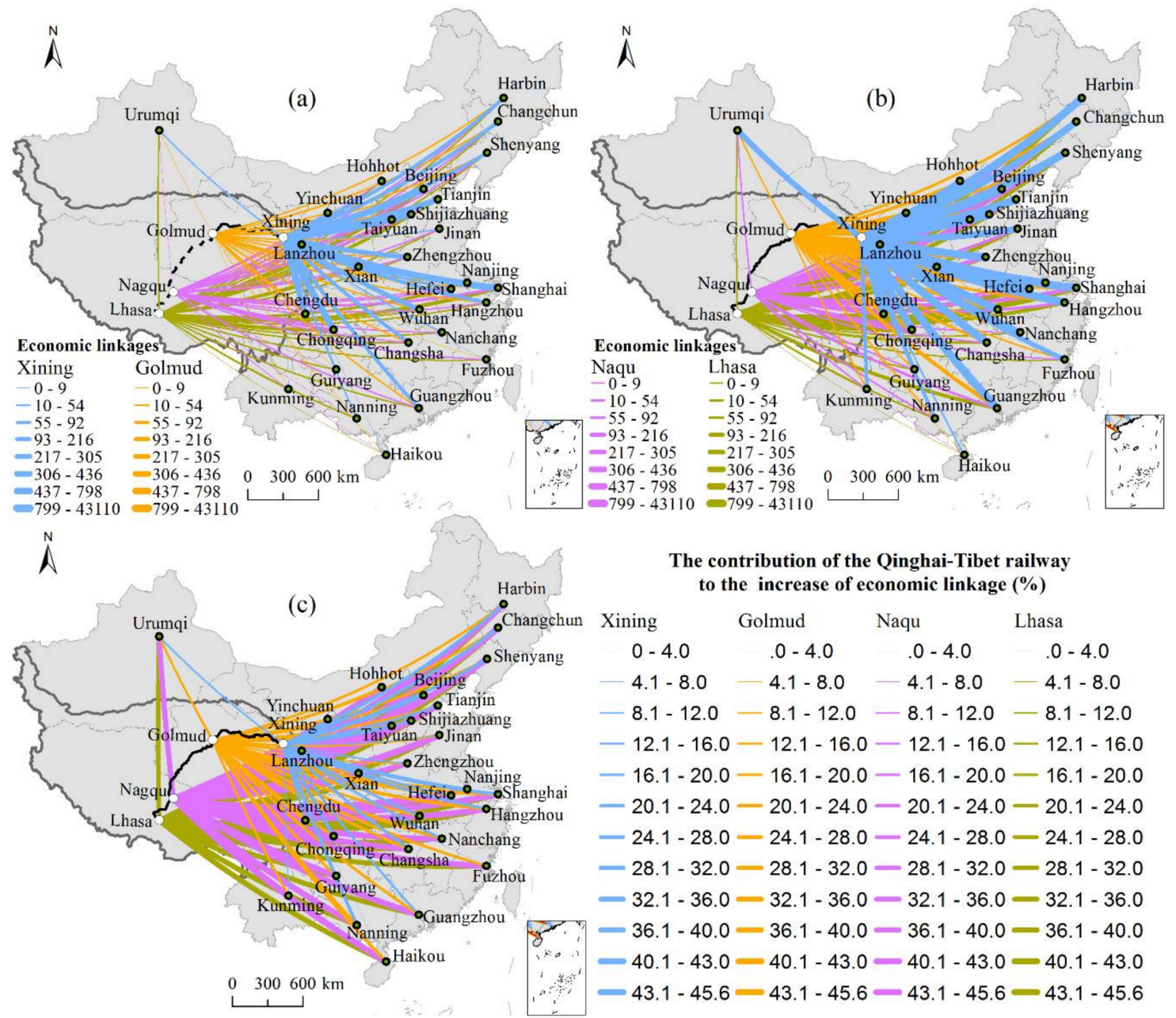

Figure 4. Improvements in economic linkages between the four cities within the Third Pole with the 29 capital cities from June 2006 to January 2013 and the contribution rate of the Qinghai-Tibet Railway (QTR). (a) Improvements in economic linkages due only to the improvement in railway-based accessibility; (b) total improvements in economic linkages for the study period; and (c) contribution rate of the QTR to improvements in economic linkages as calculated using equation (5).

In terms of economic linkages, Nagqu and Lhasa benefited the most because of the improvement in railway-based accessibility (Figure 4c). For Nagqu, the contribution rates of the QTR to the improvements of economic linkages to most cities were greater than $40 \%$, and for Lhasa, the corresponding values were 35\%. The QTR contributions to improvements in economic linkages to Shanghai, Chongqing, Taiyuan, and Hangzhou were large for all four cities. Xining, Nagqu, and Lhasa gained closer connections with northeastern China, including Harbin, Changchun, and Shenyang, based on the contribution rate. Economically, Golmud-Hangzhou, Golmud-Nanchang, and Nagqu-Haikou routes also benefited a lot due only to the improvement in railway-based accessibility.

Additionally, the spatial disparity in economic linkages to the 29 capital cities decreased from 2006 to 2013 (Figures 3 and 4). Specifically, the total economic linkage ratios between Xining and Golmud decreased from 40 in 2006, to 33 in Figure 3b, and to 29 in 2013, which enhanced the sustainability of economic growth in the Third Pole. 
Improvements in total economic linkages between the four cities and 29 capital cities were 81762.3, 3059.91, 1796.88, and 3436.06 with 4.34 and 5.98 factor increases for Xining and Golmud. The contribution rates of the QTR to improving total economic linkages for the four cities were $16.06 \%$, $17.19 \%, 42.1 \%$, and $34.95 \%$, respectively (Table 6), indicating that the QTR strengthened economic linkages in the Third Pole, especially cities in Tibet to cities in mid-eastern China from June 2006 to January 2013. Furthermore, the QTR reduced the spatial disparity in economic linkages between the Third Pole and mid-eastern China, indicating a more balanced transport system and a more sustainable economic development pattern are coming.

Table 6. Total economic linkages of the four cities within the Third Pole to the 29 external capital cities for June $2006\left(E L_{t 1}\right)$ and January $2013\left(E L_{t 2}\right)$, and the contribution rate of the Qinghai-Tibet Railway $\left(R_{Q T R}\right)$. Economic linkage units are in 100 million Yuan 10 thousand person $/ \mathrm{h}^{2}$.

\begin{tabular}{ccccc}
\hline Cities & $\boldsymbol{E} \boldsymbol{L}_{\boldsymbol{t} \mathbf{1}}$ & $\boldsymbol{E} \boldsymbol{L}_{\mathbf{Q T R}}$ & $\boldsymbol{E} \boldsymbol{L}_{\boldsymbol{t} \mathbf{2}}$ & $\boldsymbol{R}_{\mathbf{Q T R}} \mathbf{( \% )}$ \\
\hline Xining & $24,449.34$ & $37,584.12$ & $10,6211.64$ & 16.06 \\
Golmud & 614.14 & 1140.03 & 3674.05 & 17.19 \\
Nagqu & 0 & 756.44 & 1796.88 & 42.10 \\
Lhasa & 0 & 1201.06 & 3436.06 & 34.95 \\
\hline
\end{tabular}

\section{Discussion and Recommendations}

\subsection{A Railway Network Is Needed in the Third Pole to Improve Accessibility and Sustainability}

Our findings indicate that railway-based accessibilities significantly improved within the four cities in the Third Pole. These improvements reduced travel costs for economic elements, including capital, labor, and technology. For example, mineral resources and cement in Qinghai province can be transported to Tibet at lower cost [32], which is beneficial to sustainable development in Tibet.

Railway-based accessibilities also significantly improved between cities in the Third Pole and those in mid-eastern China from June 2006 to January 2013, which shortened the space-time distance between the Third Pole and mid-eastern China, especially the cities surrounding the Third Pole. This accelerated the flow of capital, labor, technology and other factors in production and reduced travel costs for economic elements. For example, passenger traffic on the QTR increased from 0.38 million in 2006 to 1.29 million in 2013 with a 2.4-factor increase. Passenger-kilometers also increased from 345 million passenger- $\mathrm{km}$ in 2006 to 1.14 billion passenger- $\mathrm{km}$ in 2013 with a 2.3-factor increase [32]. In addition, the number of tourists increased from 2.51 million in 2006 to 1.29 billion in 2013 with a 5.1-factor increase [57]. In terms of the freight transportation, the grain produced in northeastern and central China was transported to Tibet by railway and the amount of grain transported to Tibet increased 1.63 times from 2006 to 2013 [18]. Additionally, the QTR also relieve the pressure of the Qinghai-Tibet Highway (G109), which runs from Lhasa to Xining and eventually to Beijing, and is the most-used road in Tibet. The advantages of large volume and low pollution of the QTR will effectively alleviate the pollution emission problem of express transportation. In a word, besides accessibility, the construction of the QTR also improved the sustainability of transport system and development on the Third Pole.

However, the QTR alone is insufficient, and the transportation system of the Third Pole is not integrated and sustainable enough. The railway-based accessibility for the Third Pole remains poor compared with that of mid-eastern China [24], which still limits the sustainable development of the Third Pole significantly. Specifically, the length of railway in the Third Pole is still very short and railway network density is low compared with mid-eastern China. In 2013, the length of railway for all of China was 103,100 km, while the corresponding value for Qinghai and Tibet was $2404 \mathrm{~km}$, only 2.3\% [7] (Figure 5). However, the land area of Qinghai and Tibet account for $20.3 \%$ of the nation. This difference corresponds to the much lower growth rate for the length of railway in Qinghai and Tibet (Figure 5). 


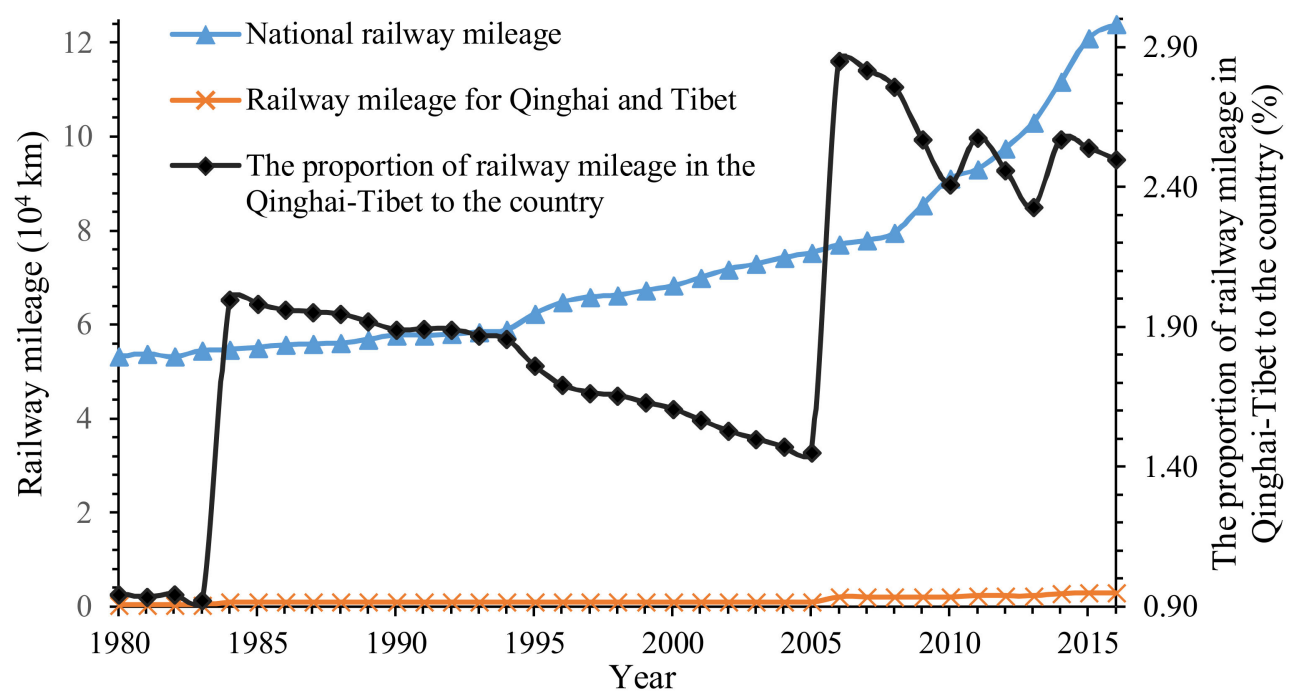

Figure 5. Railway mileage for all of China and the Qinghai-Tibet region and the proportion of railway mileage in the Qinghai-Tibet region compared with all of China from 1980 to 2016 [3-5].

With rapid economic growth in the Third Pole and the continuous strengthening of its economic linkages inside and outside the Plateau, the demand for railway transportation will necessarily increase from the perspective of sustainable development. Expanding the railway network and its capacity are urgently needed so that the railway plays a leading role in sustainable developing of the Third Pole.

The expansion of the railway network has already been proposed in the Mid-to-Long Term Railway Network Plan of China Railway (http:/ / www.ndrc.gov.cn/zcfb / zcfbtz/201607/t20160720_ 811696.html). Specifically, in addition to the Lhasa-Xigazê railway, which opened to traffic in August 2014, and the Lanzhou-Xinjiang High-Speed Railway (the first High-Speed Railway across the Third Pole), the Golmud-Korla, Golmud-Dunhuang, and Lhasa-Nyingchi railways are under construction. In addition, the proposed Xinzang railway will connect Hotan in Xinjiang and Xigazê in Tibet and lines connecting Xigaze with Yadong and Jilung and Nyalam border ports are planned [40]. When the railway network era of the Third Pole comes to fruition, the Tibet, Qinghai, Xinjiang Uygur Autonomous Region, Gansu, Sichuan, and Yunnan (Figure 1) areas will be more closely connected by railway. This will naturally increase the accessibility of the Third Pole dramatically and the economic linkages between them will be strengthened too, which will bring us a sustainable transport system and is beneficial to the sustainable development of the Third Pole in the long run.

Another factor that limits improvements in accessibility is the operation speed of the QTR, which is slow compared with railways in mid-eastern China because of ecological protection, sustainable development policies, and the harsh environment. The commercial speed for sections laid on permafrost is only $100 \mathrm{~km} / \mathrm{h}[7,58]$. Advances in technology and commercial speed of this green railway will be another way to improve the accessibility of the Third Pole.

\subsection{Suggestions for Strengthening Sustainable Economic Linkages}

The QTR has strengthened economic linkages between cities both within the Third Pole and externally with cities in mid-eastern China from the perspective of passenger transport. These ties have facilitated Tibet participating in the national market, bringing advantages to the western regions and reducing economic disparity between eastern and western China.

In addition, the QTR also stimulated the economic linkages inside and outside the Third Pole in the context of freight transportation. Using the grey prediction model GM(1,1), Li et al. [18] found that the QTR increased domestic demand in Tibet by an average of 31.12\% for 2006-2013. By 2013, the value had reached $44.05 \%$. In addition, the economic linkages between Third Pole cities and cities in mid-eastern China also strengthened due to freight transportation. Since 2006, the total amount of goods transported by the QTR to Tibet has been increasing annually, from 340,000 tons in 2006 to 
4.48 million tons in 2013, a 13-fold increase. In addition, the volume of goods transported from Tibet to all parts of the country by the QTR increased from 20,000 tons in 2006 to 710,000 tons in 2013, a greater than 3-fold increase.

More measures can be taken to enhance the sustainability of strengthening economic linkages. Specifically, the population increased slowly, i.e., there was little immigration to the regions surrounding the QTR $[32,40]$. This lack of migration is partly due to the harsh natural environment and lagging infrastructure. Therefore, in the future, more measures should be taken to attract residents who utilize the railway. For example, improving the infrastructure and developing eco-tourism are good options [40,42,59-61]. Although tourism has rapidly developed since the QTR opened to traffic, there is still room for sustainable improvement.

As shown in Figure 6, the main beneficiaries of the QTR are cities in the Third Pole. Although the percentage turnover volume in railway freight is even higher than that of highways, railway transport in the Third Pole is still developing. For 2007-2014, most goods were transported to cities in Tibet from other provinces by the QTR, accounting for more than $80 \%$; in 2007, the value was $94 \%$. However, less than $20 \%$ of goods in Tibet are exported via the QTR because the quantity and quality remain inferior to those produced in mid-eastern China [18], which is not sustainable in the long run. Government officials agree that this situation will not change over a short time period [62]. In the future, efforts should be made to develop the specialized industries in Tibet and export products to better strengthen the economic linkages to mid-eastern cities and improve the sustainability of development in Tibet. The proportion of the secondary industry in Tibet can also increase. Finally, the proposed One Belt and One Road Initiative is a good opportunity for the Third Pole to strengthen economic linkages to surrounding cities or countries [63,64].

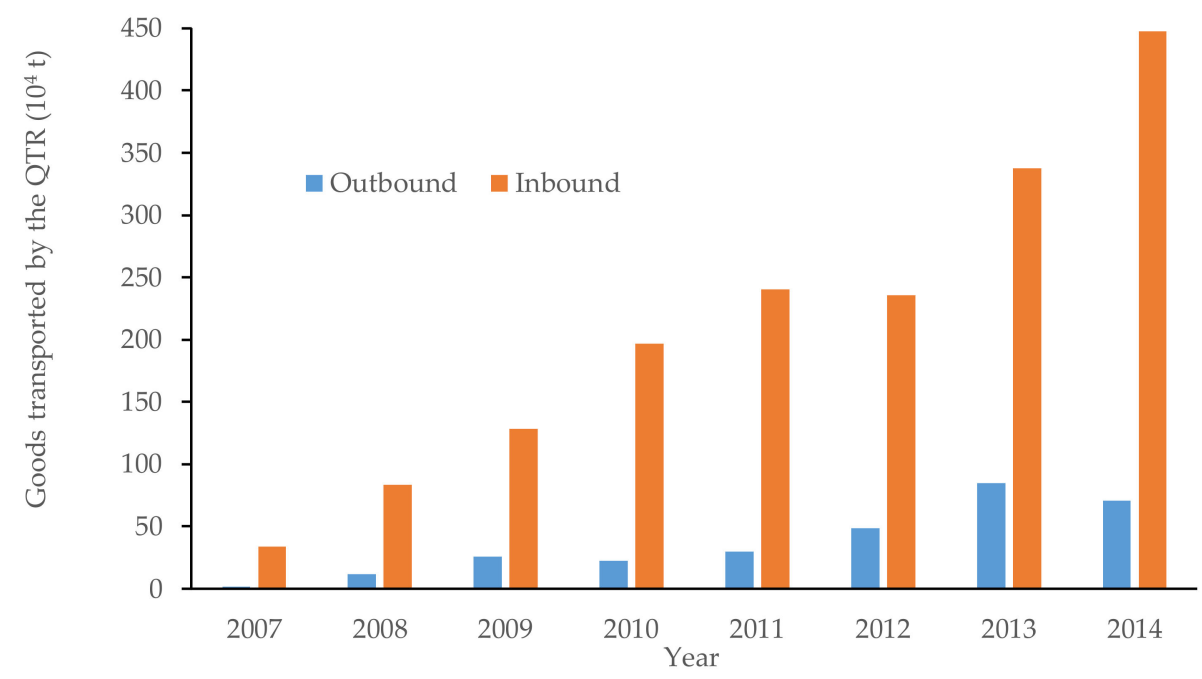

Figure 6. Imported and exported goods transported between Tibet and external cities via the Qinghai-Tibet Railway, 2007-2014.

\subsection{Limitations and Recommendations}

Generally, we calculated the contribution rates of the QTR to the improvement of economic linkages from June 2006 to January 2013. In addition, the average values for inside and outside the Third Pole are $25.29 \%$ and $27.58 \%$ respectively. The findings of this study are in agreement with previous studies showing that the QTR improved accessibility in the Third Pole and strengthened economic linkages between cities in the Third Pole and in mid-eastern China [18,41]. Specifically, Wang et al. [41] found a 33\% increase in GDP per capita in counties traversed by the railway versus those at a distance. Li et al. [18] suggested that the QTR increased the GDP of Tibet by 8\% for 2006-2013. Besides, this study has some limitations, which can be overcome in future studies when more data is available. 
Because of the unavailability of railway freight schedules, we used passenger transportation for analysis. However, freight transportation is one of the main functions of the railway and railway freight-kilometers have been higher than highway freight-kilometers, in both the average and for 18 of the 24 time points between 1990 and 2013 [32]. It can also be seen from freight transportation data in Figure 6 that the current single-direction importation is not sustainable in the long run. Once railway freight schedules are available, the analytical results will be more interesting and more suggestions concerning sustainable development in the third Pole will be provided.

In addition, the travel time from the origin to railway station or from railway station to traveler's destination, the residence time in the transfer station, and service waiting time at the railway station are not considered because of data unavailability. Compared with travel within mid-eastern China, travel between cities in the Third Pole and in mid-eastern China is long distance because of the harsh environment in the Third Pole and environmental protection policies. Therefore, not considering the travel time within cities will not introduce too much uncertainty. Because the floating population size is not available, resident population data was used in this study, which means the economic linkages are conservative estimates; the floating population size in Tibet is larger than the resident population size [40,65].

Possible extensions of this work also include alternative measures of accessibility and improving the railway-based interurban economic linkage calculation model. Daily accessibility and potential values perhaps can be used to reflect other aspects of accessibility $[20,21,66]$. In addition to transport accessibility, economic level, and population, railway-based economic linkages can also be affected by other factors, including technology, regime, culture, and division of works [67]. The gravity model we used does not account for these factors; further research that revises the model is still needed.

The economic linkages inside and outside the Third Pole enhanced because of the QTR. Although the construction of the QTR has been achieved with ecological protection at the top of the project agenda, it still disturbed the environment to some extent [68] and brought pollutions to the environment $[37,38]$. Therefore, the sustainability of the economic growth brought by the QTR needs to be assessed, which is another valuable extension of this study.

\section{Conclusions}

With the construction of the QTR, an integrated and sustainable transport system is forming in the Third Pole. Using ASTT and WATT as basic indicators, we found that the accessibilities between the four cities within the Third Pole and those between Third Pole cities and the 29 capital cities improved from June 2006 to January 2013. Furthermore, the inequalities in accessibility for the four cities decreased, which increased the sustainability of the transport system. Xining was most accessible to the external capital cities. In addition, economic linkages within the Third Pole, and between the Third Pole and mid-eastern China strengthened significantly. Because of the QTR, the economic linkages between the four cities within the Third Pole and 29 capital cities increased by $16.06 \%, 17.19 \%$, $42.1 \%$, and $34.95 \%$ respectively, with Tibet benefitting the most. Inequalities in economic linkages decreased as well as the sustainability of economic growth in the Third Pole increased.

To improve accessibility and strengthen economic linkage inside and outside the Third Pole, a railway network is needed urgently to relieve the pressure on highway transportation. In the future, efforts should be made to develop specialized industries in Tibet and export products to strengthen economic linkage to mid-eastern China from the perspective of sustainability. The sustainability of the economic growth due to the QTR also needs to be assessed.

Clearly, this is only a first step in studying railway-based accessibility and economic linkages of the Third Pole resulting from the expansion of the QTR. Further studies on this theme should be conducted as the railway network era comes to the Third Pole and railway freight schedules and floating population data are available.

Author Contributions: Conceptualization, S.L. and J.G.; methodology, S.L. and J.G.; formal analysis, S.L. and Q.D.; writing—original draft preparation, S.L.; writing—review and editing, S.L., J.G., Q.D. and T.Z.; visualization, S.L.; funding acquisition, S.L. and J.G. 
Funding: This research was funded by the National Natural Science Foundation of China, grant number 41,701,228, National Social Science Fund, grant number 14BJY057, and Fundamental Research Funds for the Central Universities, China University of Geosciences (Wuhan), grant number CUGL170823.

Conflicts of Interest: The authors declare no conflict of interest.

\section{References}

1. Qiu, J. The third pole. Nature 2008, 454, 393-396. [CrossRef] [PubMed]

2. Yao, T.D.; Thompson, L.G.; Mosbrugger, V.; Zhang, F.; Ma, Y.M.; Luo, T.X.; Xu, B.Q.; Yang, X.X.; Joswiak, D.R.; Wang, W.; et al. Third Pole Environment (TPE). Environ. Dev. 2012, 3, 52-64. [CrossRef]

3. Qinghai Provincical Bureau of Statistics and National Bureau of Statistics Survey Office in Qinghai. Qinghai Statistical Yearbook; Qinghai Provincical Bureau of Statistics and National Bureau of Statistics Survey Office in Qinghai: Beijing, China, 2017.

4. National Bureau of Statistics of China. China Statistical Yearbook; National Bureau of Statistics of China: Beijing, China, 2017.

5. National Bureau of Statistics of China. Tibet Statistical Yearbook; National Bureau of Statistics of China: Beijing, China, 2017.

6. Wang, J.; Jin, F.; Mo, H.; Wang, F. Spatiotemporal evolution of China's railway network in the 20th century: An accessibility approach. Transp. Res. Part A 2009, 43, 765-778. [CrossRef]

7. Zhang, L.; Xu, D.; Zhang, S. Studies concerning the Development and Planning of Railway Network in Qinghai and Tibet. China Railway 2016, 32-36. [CrossRef]

8. Yu, X.; Lang, M.; Gao, Y.; Wang, K.; Su, C.-H.; Tsai, S.-B.; Huo, M.; Yu, X.; Li, S. An Empirical Study on the Design of China High-Speed Rail Express Train Operation Plan-From a Sustainable Transport Perspective. Sustainability 2018, 10, 2478. [CrossRef]

9. Zhang, T.; Baker, T.H.W.; Cheng, G.-D. The Qinghai-Tibet Railroad: A milestone project and its environmental impact. Cold Reg. Sci. Technol. 2008, 53, 229-240. [CrossRef]

10. Qin, Y.; Zheng, B. The Qinghai-Tibet Railway: A landmark project and its subsequent environmental challenges. Environ. Dev. Sustain. 2010, 12, 859-873. [CrossRef]

11. Peng, C.H.; Ouyang, H.; Gao, Q.; Jiang, Y.; Zhang, F.; Li, J.; Yu, Q. Environment-Building a "green" railway in China. Science 2007, 316, 546-547. [CrossRef] [PubMed]

12. Zhou, J.; Yang, J.; Peng, G. Constructing a green railway on the Tibet Plateau: Evaluating the effectiveness of mitigation measures. Transp. Res. Part D-Transp. Environ. 2008, 13, 369-376. [CrossRef]

13. Vickerman, R.; Spiekermann, K.; Wegener, M. Accessibility and Economic Development in Europe. Reg. Stud. 1999, 33, 1-15. [CrossRef]

14. Lakshmanan, T.R. The broader economic consequences of transport infrastructure investments. J. Transp. Geogr. 2011, 19, 1-12. [CrossRef]

15. Jiao, J.; Wang, J.; Jin, F.; Du, C. Understanding Relationship Between Accessibility and Economic Growth: A Case Study from China (1990-2010). Chin. Geogr. Sci. 2016, 26, 803-816. [CrossRef]

16. Hou, Q.; Li, S.-M. Transport infrastructure development and changing spatial accessibility in the Greater Pearl River Delta, China, 1990-2020. J. Transp. Geogr. 2011, 19, 1350-1360. [CrossRef]

17. Wu, W.; Liang, Y.; Wu, D. Evaluating the Impact of China's Rail Network Expansions on Local Accessibility: A Market Potential Approach. Sustainability 2016, 8, 512. [CrossRef]

18. Li, W.; Zhang, Y. Impacts of the Qinghai-Tibet Railway on economy of the Tibet. China Railway 2016, 12-16. [CrossRef]

19. Zheng, S.; Kahn, M.E. China's bullet trains facilitate market integration and mitigate the cost of megacity growth. Proc. Natl. Acad. Sci. USA 2013, 110, E1248-E1253. [CrossRef] [PubMed]

20. Gutiérrez, J. Location, economic potential and daily accessibility: An analysis of the accessibility impact of the high-speed line Madrid-Barcelona-French border. J. Transp. Geogr. 2001, 9, 229-242. [CrossRef]

21. Jiao, J.; Wang, J.; Jin, F.; Dunford, M. Impacts on accessibility of China's present and future HSR network. J. Transp. Geogr. 2014, 40, 123-132. [CrossRef]

22. Shaw, S.-L.; Fang, Z.; Lu, S.; Tao, R. Impacts of high speed rail on railroad network accessibility in China. J. Transp. Geogr. 2014, 40, 112-122. [CrossRef] 
23. Huang, H.; Wei, Y.D. Intra-metropolitan location of foreign direct investment in Wuhan, China: Institution, urban structure, and accessibility. Appl. Geogr. 2014, 47, 78-88. [CrossRef]

24. Wang, J.; Jiao, J.; Jin, F. Spatial effects of high-speed rails on interurban economic linkages in China. Acta Geogr. Sin. 2014, 69, 1833-1846. [CrossRef]

25. Berger, T.; Enflo, K. Locomotives of local growth: The short-and long-term impact of railroads in Sweden. J. Urban Econ. 2017, 98, 124-138. [CrossRef]

26. Blanquart, C.; Koning, M. The local economic impacts of high-speed railways: Theories and facts. Eur. Transp. Res. Rev. 2017, 9. [CrossRef]

27. Mimeur, C.; Queyroi, F.; Banos, A.; Thevenin, T. Revisiting the structuring effect of transportation infrastructure: An empirical approach with the French railway network from 1860 to 1910. Hist. Methods 2018, 51, 65-81. [CrossRef]

28. Wang, Z.B.; Xu, G.; Bao, C.; Xu, J.B.; Sun, F.H. Spatial and economic effects of the Bohai Strait Cross-Sea Channel on the transportation accessibility in China. Appl. Geogr. 2017, 83, 86-99. [CrossRef]

29. Chen, Z.; Haynes, K.E. Impact of high-speed rail on regional economic disparity in China. J. Transp. Geogr. 2017, 65, 80-91. [CrossRef]

30. Zhang, Y.-F.; Ji, S. Does infrastructure have a transitory or longer-term impact? Evidence from China. Econ. Model. 2018, 73, 195-207. [CrossRef]

31. Diao, M. Does growth follow the rail? The potential impact of high-speed rail on the economic geography of China. Transp. Res. Part A 2018, 113, 279-290. [CrossRef]

32. Li, S.; Wang, Z.; Zhang, Y.; Wang, Y.; Liu, F. Comparison of Socioeconomic Factors between Surrounding and Non-Surrounding Areas of the Qinghai-Tibet Railway before and after Its Construction. Sustainability 2016, 8, 776. [CrossRef]

33. Yoshino, N.; Abidhadjaev, U. An impact evaluation of investment in infrastructure: The case of a railway connection in Uzbekistan. J. Asian Econ. 2017, 49, 1-11. [CrossRef]

34. Wang, G.; Gillespie, A.R.; Liang, S.; Mushkin, A.; Wu, Q. Effect of the Qinghai-Tibet Railway on vegetation abundance. Int. J. Remote Sens. 2015, 36, 5222-5238. [CrossRef]

35. Xu, X.M.; Zhang, Z.Q.; Wu, Q.B. Simulation of permafrost changes on the Qinghai-Tibet Plateau, China, over the past three decades. Int. J. Digit. Earth 2017, 10, 522-538. [CrossRef]

36. Chen, T.; Ma, W.; Zhou, G.Q. Numerical analysis of ground motion characteristics in permafrost regions along the Qinghai-Tibet Railway. Cold Reg. Sci. Technol. 2018, 148, 88-95. [CrossRef]

37. Zhang, H.; Wang, Z.; Zhang, Y.; Hu, Z. The effects of the Qinghai-Tibet railway on heavy metals enrichment in soils. Sci. Total Environ. 2012, 439, 240-248. [CrossRef] [PubMed]

38. Zhang, H.; Zhang, Y.; Wang, Z.; Ding, M. Heavy metal enrichment in the soil along the Delhi-Ulan section of the Qinghai-Tibet railway in China. Environ. Monit. Assess. 2013, 185, 5435-5447. [CrossRef] [PubMed]

39. Sun, H.; Zheng, D.; Tong, Q.; Chen, Y.; Li, D. Suggestions concerning the Qinghai-Tibet railway construction and socioeconomic development of Tibet. Bull. Chin. Acad. Sci. 2004, 19, 247-249. (In Chinese)

40. Chen, T.; Lang, W.; Chan, E.; Philipp, C.H. Lhasa: Urbanising China in the frontier regions. Cities 2018, 74, $343-353$. [CrossRef]

41. Wang, Y.; Wu, B. Can Transportation Investment Stimulate Local Economy? The Case of Qingzang Railway. China J. Econ. 2014, 1, 55-80. (In Chinese)

42. Tang, W.; Zhou, T.; Sun, J.; Li, Y.; Li, W. Accelerated Urban Expansion in Lhasa City and the Implications for Sustainable Development in a Plateau City. Sustainability 2017, 9, 1499. [CrossRef]

43. Jin, F.; Wang, C.; Cao, Y.; Cao, X.; Wang, J.; Dai, T.; Jiao, J. Progress of research on transportation geography in China. J. Geogr. Sci. 2016, 26, 1067-1080. [CrossRef]

44. Paez, A.; Scott, D.M.; Morency, C. Measuring accessibility: Positive and normative implementations of various accessibility indicators. J. Transp. Geogr. 2012, 25, 141-153. [CrossRef]

45. Tranos, E.; Reggiani, A.; Nijkamp, P. Accessibility of cities in the digital economy. Cities 2013, 30, 59-67. [CrossRef]

46. Curtis, C.; Scheurer, J. Planning for sustainable accessibility: Developing tools to aid discussion and decisionmaking. Prog. Plan. 2010, 74, 53-106. [CrossRef]

47. Wu, Q.T.; Fan, J.; Zhang, H.G.; Ye, Y.Y. The spatial impacts model of trans-strait fixed links: A case study of the Pearl River Delta, China. J. Transp. Geogr. 2017, 63, 30-39. [CrossRef] 
48. Falk, M. A gravity model of foreign direct investment in the hospitality industry. Tourism Manag. 2016, 55, $225-237$. [CrossRef]

49. Head, K.; Mayer, T.; Ries, J. The erosion of colonial trade linkages after independence. J. Int. Econ. 2010, 81, 1-14. [CrossRef]

50. Yu, Y.; Han, Q.; Tang, W.; Yuan, Y.; Tong, Y. Exploration of the Industrial Spatial Linkages in Urban Agglomerations: A Case of Urban Agglomeration in the Middle Reaches of the Yangtze River, China. Sustainability 2018, 10, 1469. [CrossRef]

51. National Bureau of Statistics of China. Tibet Statistical Yearbook; National Bureau of Statistics of China: Beijing, China, 2007.

52. National Bureau of Statistics of China. Tibet Statistical Yearbook; National Bureau of Statistics of China: Beijing, China, 2014.

53. Qinghai Provincical Bureau of Statistics and National Bureau of Statistics Survey Office in Qinghai. Qinghai Statistical Yearbook; Qinghai Provincical Bureau of Statistics and National Bureau of Statistics Survey Office in Qinghai: Beijing, China, 2007.

54. Qinghai Provincical Bureau of Statistics and National Bureau of Statistics Survey office in Qinghai. Qinghai Statistical Yearbook; Qinghai Provincical Bureau of Statistics and National Bureau of Statistics Survey Office in Qinghai: Beijing, China, 2014.

55. National Bureau of Statistics of China. China City Statistical Yearbooks; National Bureau of Statistics of China: Beijing, China, 2007.

56. National Bureau of Statistics of China. China City Statistical Yearbooks; National Bureau of Statistics of China: Beijing, China, 2014.

57. Su, M.M.; Wall, G. The Qinghai-Tibet railway and Tibetan tourism: Travelers' perspectives. Tourism Manag. 2009, 30, 650-657. [CrossRef]

58. Niu, F.; Lin, Z.; Lu, J.; Liu, H.; Xu, Z.-Y. Characteristics of roadbed settlement in embankment-bridge transition section along the Qinghai-Tibet Railway in permafrost regions. Cold Reg. Sci. Technol. 2011, 65, 437-445. [CrossRef]

59. Wang, D.; Niu, Y.; Qian, J. Evolution and optimization of China's urban tourism spatial structure: A high speed rail perspective. Tourism Manag. 2018, 64, 218-232. [CrossRef]

60. Xinhua News Agency. Qinghai-Tibet Railway Tourism Will Be Incorporated into National Planning. Available online: http:/ / news.xinhuanet.com/2013-10/09/c_117642139.htm (accessed on 6 June 2018).

61. Khadaroo, J.; Seetanah, B. Transport infrastructure and tourism development. Ann. Tourism Res. 2007, 34, $1021-1032$. [CrossRef]

62. Xinhua News Agency. Freight Transport of the Qinghai-Tibet Railway: "in" Is Greater than "Out". Available online: http://news.xinhuanet.com/newscenter/2007-12/17/content_7265907.htm (accessed on 6 June 2018). (In Chinese)

63. Liu, W.; Dunford, M. Inclusive globalization: Unpacking China's Belt and Road Initiative. Area Dev. Policy 2016, 1, 323-340. [CrossRef]

64. Guo, H. Steps to the digital Silk Road. Nature 2018, 554, 25-27. [CrossRef]

65. Fan, J.; Wang, H.; Chen, D.; Zhang, W.; Wang, C. Discussion on Sustainable Urbanization in Tibet. Chin. Geogr. Sci. 2010, 20, 258-268. [CrossRef]

66. Caschili, S.; De Montis, A. Accessibility and Complex Network Analysis of the U.S. commuting system. Cities 2013, 30, 4-17. [CrossRef]

67. Meng, D.; Lu, Y. Analysis of inter-provincial accessibility and economic linkage spatial pattern based on the railway network. Geogr. Res. 2012, 31, 107-122.

68. Li, S.; Zhang, Y.; Wang, Z.; Li, L. Mapping human influence intensity in the Tibetan Plateau for conservation of ecological service functions. Ecosyst. Serv. 2018, 30, 276-286. [CrossRef]

(C) 2018 by the authors. Licensee MDPI, Basel, Switzerland. This article is an open access article distributed under the terms and conditions of the Creative Commons Attribution (CC BY) license (http://creativecommons.org/licenses/by/4.0/). 